\title{
Feasibility Analysis of Flipped Classroom in Chinese Adult English Training
}

\author{
Ying Li \\ School of Foreign Languages and Literature, Beijing Normal University, Beijing, China \\ Email:611277235@qq.com
}

How to cite this paper: Li, Y. (2018) Feasibility Analysis of Flipped Classroom in Chinese Adult English Training. Open Journal of Social Sciences, 6, 35-45. https://doi.org/10.4236/iss.2018.65003

Received: April 11, 2018

Accepted: May 13, 2018

Published: May 16, 2018

Copyright (C) 2018 by author and Scientific Research Publishing Inc. This work is licensed under the Creative Commons Attribution International License (CC BY 4.0).

http://creativecommons.org/licenses/by/ $4.0 /$

(c) (i)

Open Access

\begin{abstract}
Flipped teaching has gained a growing popularity, starting from higher education and coming all the way down the academic pyramid to the primary schooling. Evidence has shown that positive results are produced in improving learning results. However, it remains to be seen whether these developments can be extended to the training outside of traditional academic settings and realize its full potential in adult English class. Therefore, essential features of the flipped classroom, adult English teachers, adult English learners and learning environment in the private language education institutions are presented to analyze the feasibility.
\end{abstract}

\section{Keywords}

Flipped Classroom, Adult English Class, Private Language Education Institutions

\section{Introduction}

When Wall Street English (one of the largest providers of adult English training around the world) is entered in the search box of Bing (one of the most widely used search engine in China), associated terms will pop out such as Wall Street English + fraud, Wall Street English + brainwashing. Moreover, Liu Xiaoguang, the co-author of Use Your English, posted an article discouraging adults from participating in oral English training of any kind on his Weibo account (Chinese version of Facebook) where he has around 280,000 followers. More shockingly, $80 \%$ of followers responding to the article echoed with his opinion, recounting their unpleasant experience in the private language training centers [1]. The disappointing learning is also reflected in the academic literature and reasons behind it are analyzed. In Tang's empirical research, two prominent obstacles lying in the way for adult English learners are the restraints of learning time and learning location [2]. Jin blames the 
disappointment to disproportionate stress on grammar but insufficient attention to practical skills [3]. Ma puts forward some general principles such as engaging adult English learners, updating and adjusting teaching materials to ameliorate the situation [4]. However, remedial measures easy to operate for teachers and learners are urgently needed to enhance the experience and improve the learning of adult English trainees, an understudied and neglected population of English learners in the research literature. Fortunately, the flipped classroom originating from traditional academic settings could provide a solution to this conundrum.

\section{Flipped Classroom}

Scholars have not reached a consensus on the definition of flipped classroom, also called inverted classroom. The widely recognized one was given by Maureen et al. from the perspective of class procedures, saying "Inverting the classroom means that events that have traditionally taken place inside the classroom now take place outside the classroom and vice versa" [5]. This means that practice exercise or problem solving previously completed by learners outside the classroom now take place inside the classroom with teachers and students present, assistance and guidance available. What used to be taught by the teacher in the form of lecture during the class are replaced by recorded video lessons viewed by learners after class. This definition sheds light on the re-ordering of in-class and after-class activities, but flipped classroom is more than that. Bishop and Verleger formulate a broader definition [6]. They propose that inside class activities include questions and answers and also group-based or open-ended problem solving while outside class learners focus on video lectures and practice exercises and close-ended quizzed.

\subsection{The Origin and Development}

Flipping teaching has generally gone through three stages.

At the very beginning, it was Eric Mazur, a physics professor from Harvard University who took advantage of computers and Internet to foster active learning by establishing computerized voting system and peer instruction model in 1990s. This brand-new approach animated traditional classes featured with monotonous lectures because it gave full play to autonomy and collaboration. His idea resonated with Alison King's appeal for teachers being a guide beside students instead of a sage on the podium. Later, other three teachers from Miami University also adopted this method in their course of an introduction to economy. So far, the flipped teaching was still at its embryonic stage when this approach was mainly applied in higher education due to the limited access to computers and Internet.

Until the $21^{\text {st }}$ century, things turn up. The affordance of technology plays a major role in popularizing this model in the $\mathrm{K}-12$ context. Jonathan Bergmann 
and Aaron Sams, two chemistry teachers in American Lincoln Highland high school recorded video classes initially for students who missed the class due to horrible weather, sports training or other school events so that they could save themselves from repetitive make-up lessons [7]. It turned out that those videos were also welcomed by students who had joined the class. These two teachers were inspired and encouraged by this large number of hits. They started uploading lecture videos and assigning them as homework before the class so that they could devote a larger proportion of in-class time to group work for problem-solving or project-making during which teachers could observe the class and provide guidance and explanation if intervention is called for. Jonathan and Aaron are forerunners in flipped instruction and set a good example for other teachers in primary and secondary education within America.

Thanks to the TED (Technology, Entertainment, Design) talk of Salman Khan: Let's Use Video to Reinvent Education, the flipped teaching is known to educators from other countries all around the world. In Salman's report, he was proud to present the data showing the popularity of the videos on the Khan Academy, which students watch at an individualized pace out of their own will or because of their teachers' order [8]. They also note down what they cannot get through by themselves and discuss the confusing points with their group members in the next day's class. What the teachers do is sense the timing of intervention and administer it properly. This kind of teaching model is acclaimed by Bill Gates as the future of education. Against the backdrop of the fast-growing development of information technology, a plethora of high-quality video lectures are readily available to learners regardless of chronological and geographical boundaries as long as they are connected to the Internet. This provides a solid foundation for the worldwide adoption of flipped learning.

\subsection{The Features}

However, the aforementioned definition is criticized too simple, covering the superficial characteristics of teaching procedures but overlooking the underlying attributes of flipped education. Yarbro stressed the significance of active learning and proposed a theory of four pillars (F-L-I-P) for flipped instruction: $\mathrm{F}$ for flexible environment, $\mathrm{L}$ for learning culture, I for intentional learning, P for professional educator [9]. His theory is complemented by Chen et al (2014) who add three more pillars (P-E-D) to make it more comprehensive: $P$ for progressive activities, E for engaging experience, D for diversified platform [10]. From their theories, highlights of flipped classroom are self-revealing.

\subsubsection{Changes in Teachers' Role}

Teacher-centered learning model is abandoned in the flipped schooling. Teachers are no longer standing in the front of class and delivering 
knowledge to the students. Instead of being the porter of knowledge, they become the facilitator, the counselor and the guide. However, this does not make teachers less relevant in the class. On the contrary, their job has become more demanding than before. First, they have to choose proper intentional learning content and decide which part should be delegated as in-class and out-class work. In this way, they can make sure the class-time is maximized and student-centered approach is applied. The content of intentional learning for videos after class hours comes from two sources. One is that teachers can choose to make their own video courses, which turns them into the designer and developer of video materials. The other option is that educators can exploit a sea of materials online, which makes them the selector and editors of online resources. It is easier said than done since two aspects are worth teachers' attention. First, the teacher has to make sure everything in the video is crystal clear so that learners have less or even no difficulties in following the lecture in the teacher's absence. Second, to keep learners fixated on the videos, teachers need some techniques. In this regard, ideas behind MOOC (Massive Online Open Course) should be borrowed. For example, the video should last no longer than 15 minutes since learners' attention span cycles in 10 - 15 minutes. Plus, each video should be ecologically complete, by which it means it starts with lead-in and ends in summary or short review [11]. Under such circumstances, the two routes require instructors to be computer literate and have basic information processing capacity. However, the most daunting task for teachers in flipped classroom is not preparing for recorded learning materials before the class but designing tightly related and relevant activities (which have to be progressive in one class and for the whole semester) such as role play, debate, interview or public speaking to ensure that learners can apply what they have learned in the videos into real life situations. Successful in-class tasks command teachers to develop superb skills to carry out activities such as giving clear instructions and progressing from low to high risk activities as well as to manage a chaotic class such as observing the class consistently and giving comments and feedback instantly.

\subsubsection{Changes in Students' Role}

Because the learning processes are completely rearranged, the role that the learners play also changes. In the traditional classroom, students are passive recipients of knowledge, preoccupied with transferring what is on teachers' PPT to their own notebooks word by word, while students become initiators, dominators and creators in the flipped teaching model. Outside the class, they learn at an individualized pace. Since the video lectures are always there, they can decide when and where to watch them and can also control how much and how fast they view the lectures. It is completely self-tuned and students can pause, backward, replay or slow down when they come to the parts where they find trouble in understanding the concepts or they can fasten the video or jump the part they find easy. Plus, they will find it rather convenient 
to review the lesson any time they need. In the physical class, most of work is done by collaboration and cooperation through which team members explore topics in greater details and solve problems in more effective way. In the process, the social interaction involving differentiated ways of persuading others and presenting ideas inspires everyone in the group so that meaningful and personal learning are more likely to occur. What's more, the teamwork offers a perfect opportunity for instructors and peers to check self-directed learning effectiveness. If they fail to prepare themselves for the brainstorming or hands-on practice in class, they will disappoint their peers and drag the whole team down when competition is involved. Next time, they will not miss any important video class and may even search for more information so as to bring more insights to the table before they are geared up for any pair work or group work. As it can be seen, autonomy plays a role in either major component of the flipped classroom. Before class, learners are counted on to take initiative to finishing the video lectures. In that case, they are able to engage themselves fully in the interaction and communication among teachers and learners. Therefore, learners have to take full responsibility for themselves and their team members.

\subsubsection{Changes in Learning Environment}

Firstly, in the flipped teaching model, knowledge is transferred to students via recorded videos before class to reduce teacher talk time and increase student talk time when class meets. This goal can be achieved without sacrificing the quantity of knowledge delivered to the students. With the learning procedures inverted and learning time redistributed, the practice literally increases the accumulative length of learning time in a covertly way by promising a flexible learning time schedule. Secondly, the priority of the class is to facilitate students to internalize what they have learned from the recorded courses by maximizing interaction among students and teachers. To that end, the class usually starts with students raising questions based on the video content and teachers responding to perplexing issues. Then the class proceeds with project-based or problem-based learning which promotes automatization (turn declarative knowledge to procedural knowledge). At this stage, seats are rearranged and settings are flexible so that groups can gather around to complete the task. Sometimes more space is saved for group presentation or intergroup cooperation. Thirdly, the interaction is not confined to physical class. It can also exist on the digital platforms which are supposed to be diversified and seamless. With a wide range of smartphone apps and laptop software at their disposal, teachers have no problem in guaranteeing the diversification. What is worth noticing is that they have to make sure the platforms seamless, convenient, ubiquitous and flexible without overwhelming their students with various platforms

\section{Theories Backing up the Model}


The principles guiding the flipped language classroom are grounded in theories, which proves that the flipped model is not irrational approach but scientifically based method.

\subsection{Interaction Hypothesis}

From the perspective of second language acquisition, interaction hypothesis, proposed by Michael Long as a supplement to Krashen's input hypothesis lends support to the underlying guidelines of flipped learning. The major claim of interaction hypothesis is that communication and interaction are necessitated in the language acquisition [12]. When interlocutors are not equipped with sufficient grammatical and lexical resources to convey their meanings in an accurate manner, they are put in a position to negotiate meaning by receiving positive and negative feedback and producing modified output. In the flipped classroom, myriad opportunities are created for interaction and communication among learners and instructors as well as among students. In the in-class activities, particular tasks are designed by teachers to make the linguistic characteristics of target language stand out. Learners are implicitly lead to engage in interaction with target language. Unlike native speakers, learners' language competence may fall short. When they make mistakes, teachers and their partners should point out their errors in a good timing and allow them to correct their mistaken linguistic output. If necessary, teachers or other competent learners can provide explanation of the semantic and syntactic features of specific language points. When they fail to employ suitable language structures to express their ideas, they are encouraged to modify their output through negotiation of meaning in real-time situation to promote mutual comprehension and smooth interactive communication.

\subsection{Taxonomy of Cognitive Domain}

Another influential theory that applies to this teaching model is Bloom's revised taxonomy of cognitive domain. Learning falls into six levels (from the lowest level to the highest level): remembering, understanding, applying, analyzing, evaluating and creating [13]. In the traditional classroom, most of time is devoted to the lower-order thinking through face-to-face lectures when students are required to recognize, recall and understand the messages they obtain from the teacher as well as through question and answer sessions when students are expected to display their understanding and interpret the basic concepts of what they have learned. It can be clearly seen that little time is saved for practicing the higher level cognitive domain. In most cases, teachers will leave that part for homework, which obviously is not an optimal choice since teachers are most needed but not readily available. However, the flipped language teaching consists of two major components: in-class activities and outside-class activities. Basic cognitive skills are rehearsed outside 
the class. Individual students are assigned pre-recorded video lectures and some complementary reading materials to remember and understand the basic concepts and principles. In language class' case, students need deal with vocabulary usage and grammar rules at home independently. They are also welcomed to search for more information based on the content of video courses. The higher-order skills in the cognitive domain are centralized in the brick and mortar class where teachers and students engage in various tasks aimed to hone their analyzing, applying, evaluating and creating skills. Tasks in language classes can take a variety of forms such as discussion, presentation, debate or projects.

\section{Feasibility Analysis}

\subsection{Adult English Teachers in Chinese Private Language Schools}

The major difference between teachers in Chinese public schools and private training institutions is the sense of threat and the desire for challenges. To establish and sustain their presence in the market, private language training institutes in China give priority to managing their human resource, especially the teaching staff who determine whether their clients will stay or leave. One of the policies is a strict reward and punishment system to the effect that teachers who help their learners achieve the target goals will be rewarded or get a salary raise and vice versa. To survive in the fierce competition with their counterparts and to climb higher on the career ladders, adult English teachers in these facilities are willing to take challenges and accept new things in the hope to help adult learners to improve their English level. Incentivized by the external and material rewards as well as internal and spiritual accomplishments, they also excel at making innovations by integrating their previous language learning experience and existing professional expertise with emerging teaching approaches to solve learners' problems. On top of that, these teachers have no difficulty in handling office technology including making powerpoints, searching information as well as obtaining and processing multimedia materials and resources.

In a nutshell, instructors who teach adult English in private language centers are qualified to adopt the new approach when software and hardware are all set.

\subsection{Adult English Learners in Chinese Private Language Schools}

\subsubsection{Strong Motivation}

Unlike college students whose parents take care of the tuition, most Chinese adults who study in a private language training institute normally have to pay the fees out of their own pocket. Understandably, they display great desire, tremendous enthusiasm and strong motivation to learn English and to learn it well.

Gardner and Lambert classified motivations into two types: integrative and 
instrumental motivation [14]. English learners motivated by integrative reasons are those who have an interest in being integrated into the second language community and communicating with its members; while those motivated by instrumental reasons are learners who treat English as an instrument or a tool for other purposes.

With the economic globalization, employers have a higher demand for workforce who can communicate with people from foreign backgrounds, especially those from English-speaking world. Plus, Chinese government is pushing hard its Belt and Road Initiative. Any economic institute who sets its heart on cashing in on the policy are in desperate need of competent employees speaking a second language, mainly English, the dominant one. Thus, speaking English becomes one of the employability skills which the office or factory workers have to acquire in order to survive in the $21^{\text {st }}$ century job market. Besides this, English is one of the subjects that Chinese people have to pass in their postgraduate or doctor entrance examination [14]. Hence, most adults sacrifice their leisure time to learn English because they want to keep up with the ever-changing society and be competitive in the workplace and in the community. However, not all people learn English for vocational or academic purposes. Some people learn English because they try to integrate into the local culture when they migrate abroad or communicate with their foreign spouses and relatives-in-law. Others learn English to make their life easier when they travel abroad and help their children with English homework.

The strong motivation, instrumental or integrative, will lead to positive learning attitudes and high self-efficacy, which breeds commitment to completing video courses and engaging in interactive activities and thus facilitates learning process and results in the flipped learning journey.

\subsubsection{Self-Directedness}

Adults are featured with an independent self-directing personality. As an independent person, adults believe that they are able to take responsibility for the consequences of their own decisions and actions. Therefore, they hope others to respect and acknowledge their independent status and social functions when they are engaged in the social activities. If they are confronted with obstacles, they expect guidance and help from their teachers, instead of orders from authoritative figures. This character can be attended to in the flipped classroom characterized with the student-centered teaching model advocating for teachers being a guide on the side instead a sage on the stage. Therefore, teachers would not be dictators in the class but friends to learners in a democratic learning atmosphere.

In addition, this self-directedness endows adults with large self-learning capacity including skills to employ strategies. They are able to monitor and reflect on their own learning process in a self-regulated way and adjust their learning strategies in a timely fashion. Therefore, they can make clear goals 
and detailed plans so as to complete learning tasks within the shortest period of time to achieve the best learning results and in the most suitable manners. Meanwhile, compared with children, they are more conscious of applying cognitive strategies involving processing information. For example, when they encounter problems concerning memorizing vocabulary or grammatical rules, they are able to mobilize their existing knowledge and associate what's known with what has been freshly learned so that they can keep those language structures in mind via meaningful learning. For that reason, they are capable of studying the assigned video courses independently.

\subsubsection{High Efficiency}

Limited learning time, coupled with rocketing high cost and previous language learning experience, contributes to the fact that Chinese adult English learners hope for maximum return on investment.

First, adult English learners have to shoulder different responsibilities in the family and in the society, so they cannot spend as much time as full-time college students in learning English. Usually, they have to squeeze time out of their tight schedule during weekends or holidays. In China, most language training schools prefer to locate their branches in the downtown areas well connected by subway or bus lines but distant away from residential regions. If they are lucky to have a training center near where they live or work, they can save two or three hours' commuting time.

Otherwise, the time spent in the round trip could amount to the class session each time. Besides, they are charged by the hour in the private language training institution. Two levels of adult English courses, less than 150 class hours, spreading a whole year, could cost them 20,000 to 40,000 yuan (the unit fee depends on the reputation and quality of the institution). For lower or middle-income Chinese workers, the fee will account for a large portion of their overall expenses.

In addition, the accepted body of knowledge will serve as a reference or even a decisive factor for whether they should learn the language, in which area they should deepen their expertise, and in which way they should proceed and access their learning. This may explain why they are quite demanding in choosing teachers. Considering their previous language learning experience in high school and college, they certainly do not hope teachers to occupy the precious class time to explain the grammar rules they already know or present word expressions they can find in other places free of charge, say in the dictionary or online. It is understandable that they want to maximize student talk time to gain a sense of achievement when they walk out of that classroom. So every minute in class counts.

Under such circumstances, the bright sides of flipped teaching come to sight. For one thing, adult English learners can conduct informal learning outside the class with the help of recorded lectures. They can watch the video courses on their portable devices such as smartphones or tablets while they 
are waiting for the bus, driving to work, performing house chores, or even using the toilet. They normally take class once a week or twice or third times a week. At the intervals, they have plenty of time to digest the content in the video and get ready for the physical class. In this way, adult learners can avail themselves fully of chopped time in secrecy. When they walk to the classroom, they are supposed to take the initiative to present their problems noticed during the preview and focus on what really troubles them. And then most of class time is devoted to practicing what they have learned and deepen that knowledge. Accordingly, they can achieve the best results within the fewest learning hours at the lowest cost.

\subsubsection{Rich Life Experience}

Grown-ups have around or more than two decades' life experience under their belt, which means their cognitive structures differ from that of children. While performing various duties in their work and life, they accumulate rich social experience. The background knowledge and life experience provide raw materials for oral communication. Therefore, in speaking English classes, they are able to express themselves based on what they have gone through so that they will not feel tongue-tied due to lack of content. This is also true in written classes where adults can give insights to some essay topics. This advantage saves teachers and students from awkwardness and embarrassment in the flipped classroom abundant with discussions. What's worth mentioning is that teachers have to scaffold and prepare their learners for those tasks since most of adult English learners are basically beginners who lack means to express themselves.

\subsection{Learning Environment}

When a potential customer enters one of the top language training chainstores in China such as EF (Education First), NO(New Oriental School), MT (MeTen), they will be impressed by the professionally dressed receptionists and teachers and also be amazed by the well decorated and equipped classrooms and self-study rooms. To attract customers and get them onboard, these institutions never show reluctance to invest in their hardware: projectors, computers, web whiteboard, tablets and even VR (virtual visual) equipment. They know they cannot afford to lose the preemptive opportunities in installing any new generation of education technology which can stimulate and facilitate language learning. As for the primitive video recording equipment, these organizations have no problem in providing their teachers with technical support. Take new oriental school for example, it has an online course department in charge of recording teachers' classes, editing video courses and selling them online. With a database already available, it would be much easier for them to implement the flipped model as long as they develop a series of classes complimenting with their online courses. Some companies are financially adequate to develop their own app on which they can 
upload the video lectures. This will avoid illegitimate distribution of their products and protect the intellectual property rights. At last, there is no worry that learners cannot access the videos since any learner who can afford the tuition fee owns at least one computer and one smartphone. These conditions clear the way towards the flipped instruction.

\section{Conclusion}

The flipped learning and teaching method empowers students with autonomy and ownership inside and outside the classroom, provides learners with numerous opportunities for active and interactive learning and creates a flexible learning environment in which learners can maximize their learning efficiency. All of these are what Chinese adult English learners wish for and prepare for. With respects to hardware, Chinese private training agencies are armed with advanced and necessary equipment for this teaching approach. Finally, as for teachers, they are competent to take on the journey of adventure with the flipped classroom. Therefore, it is feasible for the Chinese private training institutions to apply this model in the adult English class. With a flipped teaching approach in Chinese adult English class, the adult English learners can overcome serious difficulties of learning English and have their active skills (listening and speaking) improved; the adult English teachers will gain a sense of achievement and show more enthusiasm in their career; the whole adult English training industry will take a turn for the better.

\section{References}

[1] Liu, X.G. (2017) Don't Join in Oral English Training of Any Kind. https://mp.weixin.qq.com/s/TzxB8JzOMli1d12SqcLGpg

[2] Tang, S.F. (2014) A Research of Mobile Learning Based on Features of Adult English Learners. Adult Education, 34, 104-106.

[3] Jin, X.Y. (2015) Problems in Adult English Grammar Class and Solutions. Overseas English, 18, 61-63.

[4] Ma, A.Y. (2012) Principles to Improve Adult English Learning Results. Adult Education, 32, 105-106.

[5] Lage, M.J., Platt, G.J. and Treglia, M. (2000) Inverting the Classroom: A Gateway to Creating an Inclusive Learning Environment. Journal of Economic Education, 31, 30-43. https://doi.org/10.1080/00220480009596759

[6] Bishop, J.L. and Verleger, M.A. (2013) The Flipped Classroom: A Survey of the Research. Conference of $120^{\text {th }}$ ASEE Annual Conference and Expostion, Atlanta, Georgia.

[7] Bergmann, J. and Sams, A. (2014) Flipped Learning: Gateway to Student Engagement. International Society for Technology in Education, Eugene, Oregon.

[8] Khan, S. (2012) The One World Schoolhouse: Education Reimagined. One World Schoolhouse: Education Reimagined. Hodder \& Stoughton, London.

[9] Yarbro, J., Arfstrom, K.M. and McKnight, K. (2018) Flipped Learn: Extension of a Review of Flipped Learning. http://www.flippedlearning.org/research

[10] Chen, Y., Wang, Y., Kinshuk and Chen, N.S. (2014) Is Flip Enough? Or Should We Use the Flipped Model Instead? Computers \& Education, 79, 16-27. https://doi.org/10.1016/i.compedu.2014.07.004

[11] Wang, Y.G. (2014) Mooc: Features and Learning System. Education Study, 9, 
112-120.

[12] Ellis, R. (2008) The Study of Second Language Acquisition. 2nd Edition, Oxford Applied Linguistics, Oxford University Press, Oxford, 243-292.

[13] Bloom, B.S., Engelhart, M.D., Furst, E.J. and Krathwohl, D.R. (1984) Taxonomy of Educational Objectives: the Classification of Educational Goals. The Classification of Educational Goals, Handbook 1, 16, 58-60.

[14] Gardner, R.C., Smythe, P.C. and Brunet, G.R. (1977) Intensive Second Language Study: Effects on Attitudes, Motivation and French Achievement. Language Learning, 27, 243-261. https://doi.org/10.1111/j.1467-1770.1977.tb00121.x 